\title{
DESIGNING A NEW TYPE OF DRIVE UNIT FOR THE ANALYSIS OF SMALL PLASTIC GEARS
}

\author{
Marada Imre \\ PhD hallgató, Miskolci Egyetem, Gép-és Terméktervezési Intézet \\ 3515 Miskolc, Miskolc-Egyetemváros, e-mail: maradaimre@gmail.com \\ Bihari János \\ egyetemi docens, Miskolci Egyetem, Gép-és Terméktervezési Intézet \\ 3515 Miskolc, Miskolc-Egyetemváros, e-mail: machbj@uni-miskolc.hu
}

\begin{abstract}
When testing small plastic gears, the accuracy is always a problem. These gears are typically designed to perform their function with certainty, while other operating factors, such as noise, efficiency, and the similar factors play a marginal role in design or are not even considered (VDI 2731, 2009). However, when designing such gears, the designer is forced to face the limitations of known and recognized standards, guidelines, and methods, as well as the special characteristics of the installation environment. The problems arising from these can be explored mainly through experiments. Experiments with gears can be costly in this case because they often require at least two orders of magnitude more accurate measuring instruments than we have been accustomed to with normal-sized gears, and obviously appropriate equipment is required. In many cases, the use of drive units described in this article is a good solution to the problem of costly equipment. These drive units can contain gears of a given wheelbase, and their output and input shafts have the same external dimensions. This simplifies the problems of the equipment and makes the effects of the errors well comparable. This article describes the purposes and how we have used this type of drive units at the Institute of Machine and Product Design so far, what limitations they have, and what solutions can be used to develop these drive units to be able to perform more accurate tests.
\end{abstract}

Keywords: small plastic gears, drive unit, analysis

\section{Definitions}

\section{Small gear:}

In this article, "small gear" means a gear having a maximum module of $0,5 \mathrm{~mm}$ and a maximum characteristic size not exceeding $30 \mathrm{~mm}$.

\section{Plastic gear:}

In our current research, we have used only cylindrical gears with involute profile and external straight teeth, made of polyamides with a yield stress of $80-85 \mathrm{~N} / \mathrm{mm}^{2}$, a tensile strength of at least $50 \%$ and a modulus of elasticity of $3200-3000 \mathrm{~N} / \mathrm{mm}^{2}$, and gears made of polyoxymethylene materials with a yield stress of $70 \mathrm{~N} / \mathrm{mm}^{2}, 30 \%$ elongation at break and $3000 \mathrm{~N} / \mathrm{mm}^{2}$ modulus of elasticity. 


\section{The previously used drive units}

In-service testing of gears usually requires structures that secure the gears in the correct positions and allow for drive and load, possibly allowing the testing of the entire system, e.g., various bearings. These structures are typically test benches. In many tests of small plastic gears, building a suitably universal test bench is typically very expensive. Therefore, for the examination of the recirculation torque and the reactive loads, we have previously developed a drive unit which, when placed in simple devices, was able to perform measurements at specific settings, thus eliminating the complicated adjustment possibilities of the test benches. When designing the drive units, we took into account that in many tests of small gears, it is advisable to rotate the entire drive unit, because this provides an opportunity to use, for example, static torque measuring equipment. The drive units were designed according to the following principles:

1. Each drive unit can contain a pair of gears.

2. They must also be capable of measuring the recirculation torque and the reactive loads so that, where appropriate, the tests can be combined.

3. They must have rounded outer corners so that there is no collision problem with the clamps.

4. High rigidity in bearings.

5. Sufficient space for gears, taking into account wheelbase tolerances and the various possible layouts.

6. For mounting, the housings must be divided in a direction perpendicular to the axes of the gears, ensuring the exact positioning of the two housing halves.

7. The weight of the housings should be as small as possible, otherwise they may affect the results of the recirculation torque measurement.

8. With the tools at our disposal, it can be produced in as many variations as possible from a given basis.

Point 8 in this case meant a Roland MDX-650 CNC milling machine, that tool is capable of producing parts with adequate precision. However, the production of a single housing would have taken 60 hours if the parameter given in point 7 were not violated. Therefore, the drive units were eventually manufactured from ABS material with FDM 3D printing and finished with precision milling. The cutting parameters of the milling were also a problem, and these were determined experimentally, as neither literature nor experience was yet available for machining parts made with 3D printing. The experiments were performed on several materials, the best results could be obtained with ABS, so the choice was made for this material. This method allowed the costly and slow precision milling operations to be limited to the holes of the shafts/bearings, thus reducing the production time of the gears to an average of two hours.

Basically, two drive unit types with plain bearing (Fig. 1) and roller bearing (Fig. 2) were developed and manufactured in several versions. The experiments at the time required four different wheelbases as well as a design simulating a typical fault due to housing distortion, so the drive units were made in a total of five versions. The different wheelbases are designed according to the most important values of the ISO tolerance range for operation. The simulated error was the skew formed when the housing was distorted, for which the bearing of one of the shafts was inclined by $3^{\circ}$ (VDI 2731, 2009). 


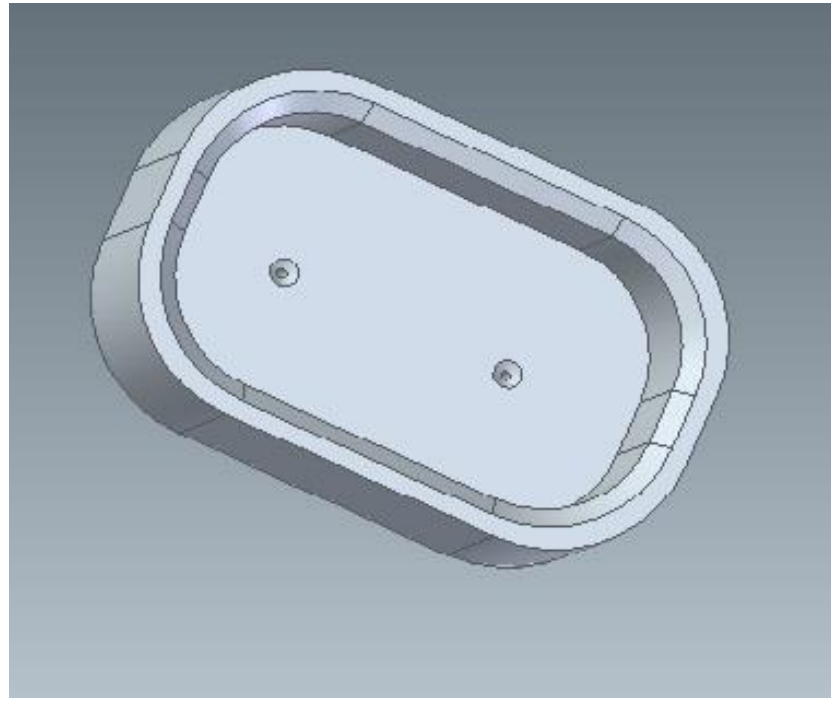

Figure 1. Housing of the drive unit for plain bearing
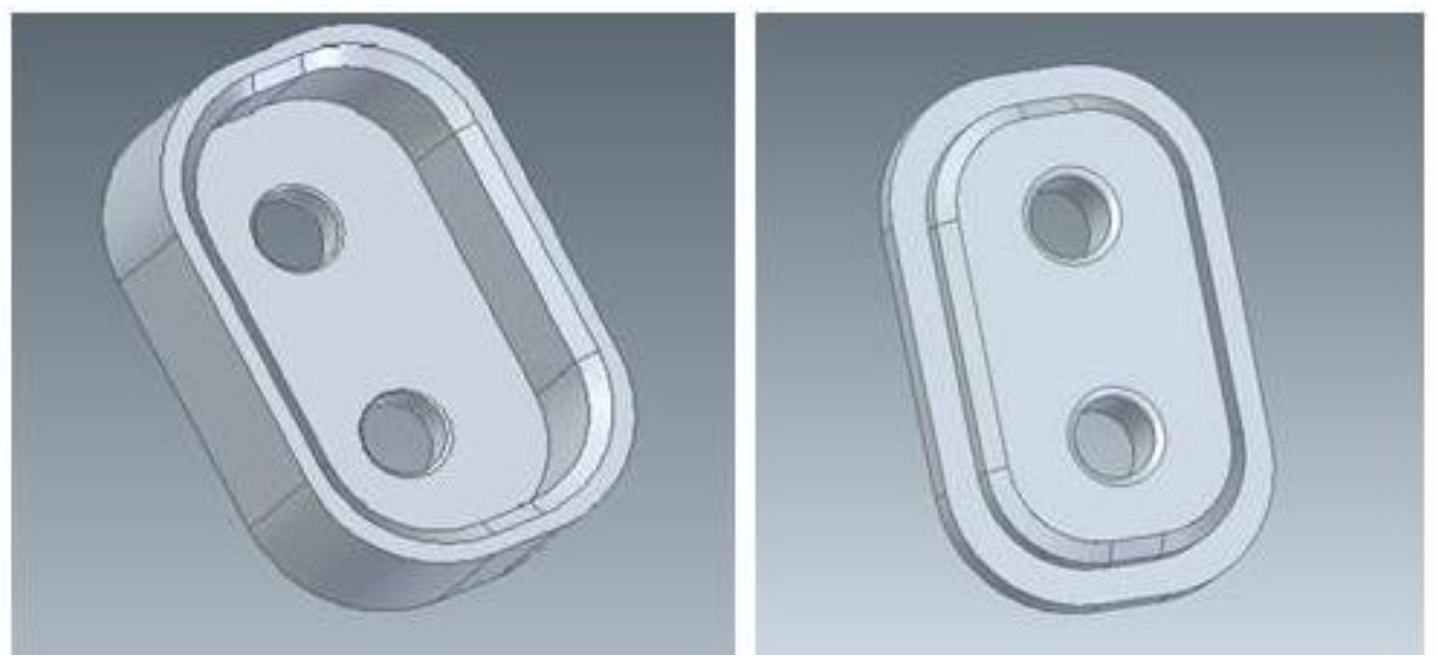

Figure 2. Housing and cover of the drive unit for roller bearing

\section{Applications of previous drive units and results achieved}

\subsection{Applications of drive units}

Drive units were used to measure recirculation torque and analyse the effects of reactive loads. When measuring the recirculation torque, one specific shaft of the drive unit is rotated and there is no load on the other shaft. Based on such measurements, a number of errors or natural, but e.g., quality assurancerelevant processes can be identified (Bihari, 2014; Bihari and Kamondi, 2011). The layout of the measurements is shown in Figure 3. In this measurement, the torque measuring shaft is stopped, one of the shafts of the drive unit is connected to it, and the drive unit is rotated. This is necessary because a static torque measuring shaft can also be used, which requires significantly less effort than otherwise, 
with the accuracy required here, and the preparation time for the measurement is also significantly shorter.

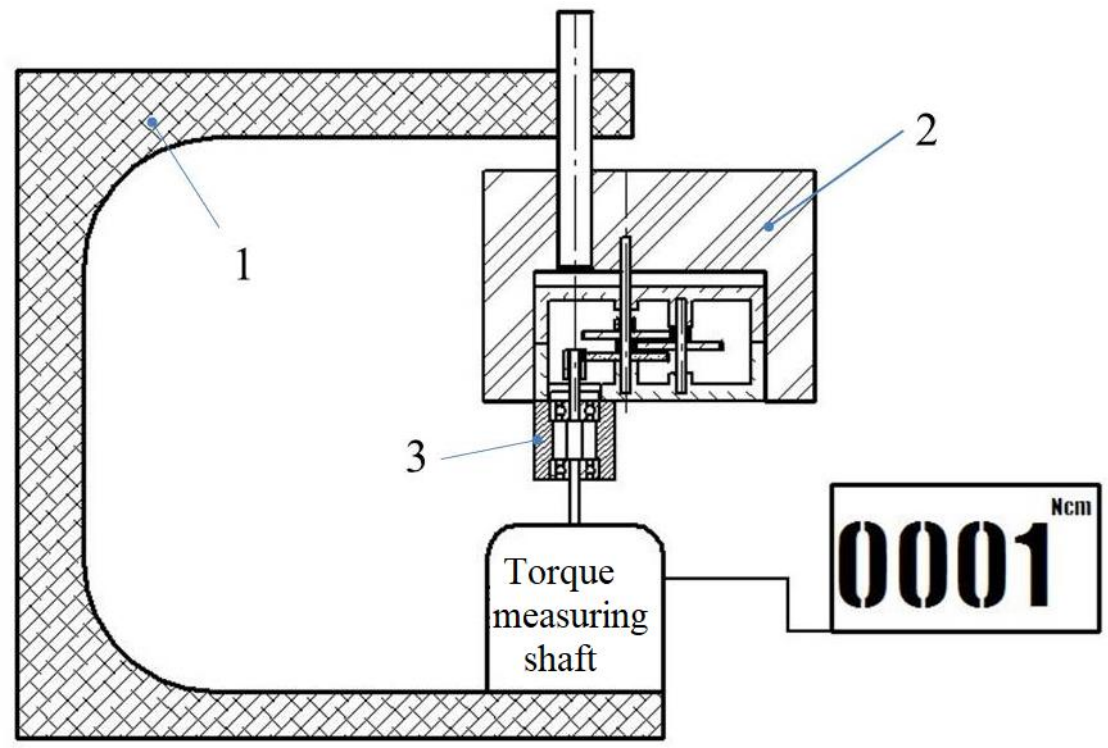

Figure 3. Measuring system for measuring the recirculation torque of drive units with small gears. 1: frame; 2: clamp of the drive unit; 3: connection element for the drive gear

Reactive loads can cause difficult-to-diagnose problems in gearboxes equipped with small plastic gears if the gears also perform a support function (Sarka et al., 2021). As this is a typical additional application, especially for multi-stage drive units, it is worth researching the effects of such loads thoroughly. To test the effect of the reactive loads, one of the gears must be fixed and a repetitive load must be applied to the shaft of the other gear. In previous drive units, the fastening was done with a screw through the hole in the gear, and the load was provided by a steel weight. The layout of the measurement is shown in Figure 4.

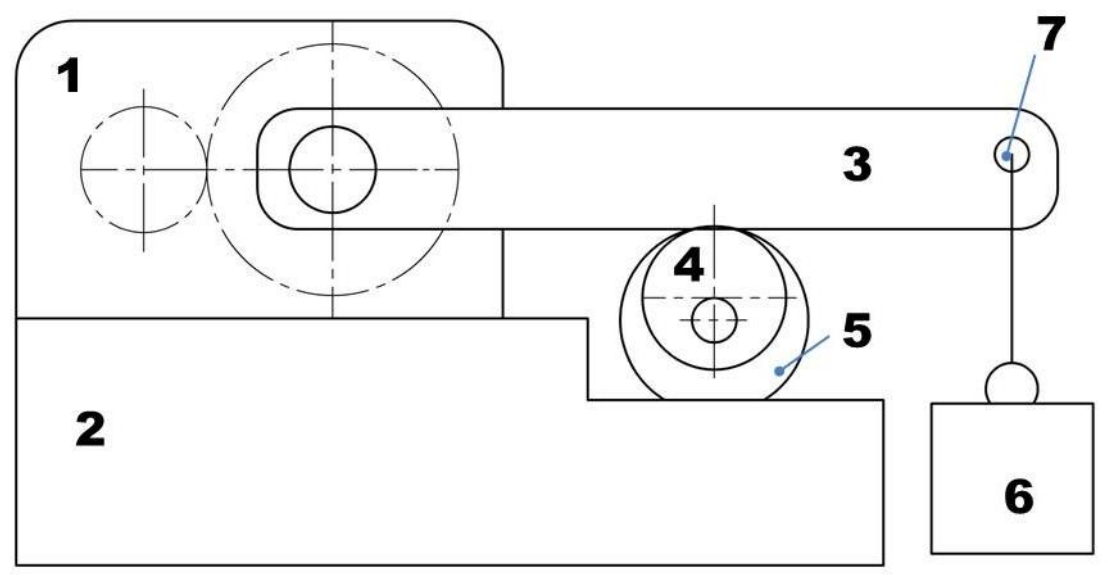

Figure 4. Layout of the reactive loads test 
A lever (3) is directly connected to the output shaft of the drive unit (1). The drive unit (1) and the drive motor (5) are mounted on the base (2). An eccentric disc (4) is mounted on the motor shaft, above it the lever is situated. When the motor is running, it raises the lever, this condition is shown in the figure. When the eccentric disc rotates, the lever loads the gears. The load is provided by a weight (6) suspended at the end of the lever. The weight is suspended from the arm by a joint (7). The angular rotation of the lever can be adjusted by adjusting the position of the motor. The number of loads is thus one per the rotation of the motor, so the number of loads per time depends on the motor speed. The magnitude of the load is determined by the magnitude of the weight.

\subsection{Results achieved with the help of drive units}

With the help of drive units, we were able to perform a number of measurements and proved, among other things, that measuring the recirculation torque can detect certain geometrical sizing and manufacturing errors and that these errors can be distinguished from processes, that are natural in mass production, but results inadequate recirculation torque, such as burr detachment or lubricant distribution.

We have also demonstrated that reactive loads can lead to significant local temperature rise in the teeth in contact.

\section{Why is it necessary to develop new drive units?}

The drive units used so far are only suitable to prove the measurability of the phenomena listed above. However, they are very limited in their ability to collect data for high-reliability error analysis with their help. The same is true in the case of reactive loads, the effect of the loads can be proved, but these gears are not suitable for the precise determination of the effects. However, since the design of the original drive units, technology has evolved greatly, and processes and materials have become available, that would not have been economically viable before. Examples are higher-precision FDM printers and the special materials that can be used with them, or SLA printers. This makes possible to design more advanced, accurate, and universal drive units.

\section{Requirements for new drive units/Summary}

Previous drive units could only contain gears consisting of the same number of teeth. For new drive units, different gear ratios must be feasible. This can be solved with eccentrics or replaceable covers.

In previous drive units, the clamping surfaces did not allow for accurate repetition, a drive unit could not be returned to the clamp in the same way within $0.05 \mathrm{~mm}$, which meant that the impact during rotation was always different. New drive units must be designed in such a way, that they are always connected to the clamp in the same way within the required accuracy.

Previous drive units could not be combined, multi-stage drives could not be created from them. This would not have been necessary either, as the gear ratio was 1:1 for each. However, to study the interaction of faults, it is necessary to be able to design several stages in the drive units.

In the plain bearing versions of the previous drive units, the bearing bush was made of the housing material. Injection moulding methods that are suitable for combining different materials are already well known and are often used by manufacturers of plastic gearboxes. Therefore, there is a need for housings, in which plain bearings made of materials other than the housing material can be installed.

In addition, several points in the original list of requirements still need to be implemented, namely: 
1. They must also be capable of measuring recirculation torque and reactive loads so that, where appropriate, the tests can be combined.

2. High rigidity in bearings.

3. Sufficient space for gears, taking into account wheelbase tolerances and the various possible layouts.

4. For mounting, the housings must be divided in a direction perpendicular to the axes of the gears, but multiple division is advisable (e.g., middle part with two covers).

5. The weight of the housings should be as small as possible, otherwise they may affect the results of the recirculation torque measurement.

6. With the tools at our disposal, it can be produced in as many variations as possible from a given basis.

\section{Literature}

[1] VDI 2731 Mikrogetriebe, (2009). Grundlagen. BeuthVerlag, Berlin.

[2] Bihari, J. (2014). Kisméretủ műanyag fogaskerekes hajtások hibái. GÉP, 65(2), 19-22.

[3] Bihari, J., Kamondi, L. (2011). Kis méretủ mủanyag fogaskerekek vizsgálata. GÉP, 62(7-8), 21-24.

[4] Sarka, F., Bihari, J., Takács, Á.**, Tóbis, Zs. (2021). Test method for investigation of reactive loads on gear drives with supporting function. Lecture Notes In Mechanical Engineering 22, 265-272., 8 p. 